\title{
Role of breast ultrasound in evaluating the response of locally advanced breast cancer to neoadjuvant anthracycline chemotherapy in Ibadan
}

\author{
Soyemi $\mathrm{TO}^{1}$, Ayandipo $\mathrm{OO}^{2 *}$, Ademola $\mathrm{AF}^{2}$, Obajimi GO${ }^{3}, \mathrm{Obajimi}^{\mathrm{MO}}{ }^{1}$ and Ogundiran $\mathrm{TO}^{2}$ \\ ${ }^{1}$ Department of Radiology, University College Hospital, Nigeria \\ ${ }^{2}$ Division of Oncology, Department of Surgery, College of Medicine, University of Ibadan and University College Hospital, Nigeria \\ ${ }^{3}$ Department of Obstetrics and Gynecology, College of Medicine, University of Ibadan and University College Hospital, Nigeria
}

\begin{abstract}
Introduction: Neo-adjuvant chemotherapy (NAC) is increasingly used in the treatment of patients with large and locally advanced breast cancer (LABC). It aims at downsizing the primary tumor thereby minimizing micro-metastatic disease. There exists variable response following neo-adjuvant chemotherapy and the objective of this study was to determine the potential role of breast ultrasound in monitoring the clinical response of LABC to NAC.

Methods: One hundred and twenty (120) consecutive patients with LABC scheduled to have six cycles of anthracycline-based neo-adjuvant chemotherapy were recruited for the study at the Surgical Oncology Unit of the University College Hospital, Ibadan. Eligible patients had a pre-chemotherapeutic breast ultrasound (US). Follow up breast US was performed 3 weeks after completion of each cycle of chemotherapy. Ethical approval was obtained from the University of Ibadan/ University College Hospital Ethics Committee and data analyzed using SPSS Software version17.0, Chicago, Illinois.

Result: The mean age of the women studied was $44.17 \pm 9.07$ years with peak age group in the $5^{\text {th }}$ decade. Breast ultrasound detected more multifocal disease in 42 (35\%) patients compared to $2(1.7 \%)$ patients on clinical breast examination (CBE), so also detected nodal disease in $5 \%$ more patients than CBE. There was $91.6 \%$ agreement between $\mathrm{CBE}$ and breast ultrasound in nodal staging, $\mathrm{p}=0.001$ compared to $60 \%$ in tumor staging, $p=0.52$. A good clinical response was found in 106 $(88.3 \%)$ patients exposed to neo- adjuvant chemotherapy. No predictor of tumor response to neo-adjuvant chemotherapy was found in this study.

Conclusion: Breast ultrasound is more appropriate than $\mathrm{CBE}$ in the pre- or post-chemotherapy assessment of tumor size and nodal staging in patients with breast cancers. In this study, breast ultrasound agreed more with clinical breast examination in nodal staging than in tumor staging and it was vital in the detection of multifocal breast cancers. Although it is quite difficult to predict patients that would respond well to NAC, anthracycline- based chemotherapy remains effective in patients from low income countries.
\end{abstract}

\section{Background}

Neoadjuvant chemotherapy (NAC) has become a veritable tool for down-staging of locally advanced breast cancer (LABC) [1,2], immediate treatment of micro metastases $[3,4]$ and direct assessment of drug efficacy [5]. It has become as pivotal as adjuvant chemotherapy (AC) in the management of locally advanced breast carcinoma. In the sub Saharan African setting the typical patient often presents with an advanced tumor [6,7] that often precludes immediate surgical extirpation. Approximately $50 \%$ of breast cancer patients seen in our oncology practice require NAC to downstage and render the tumor amenable to loco-regional surgical treatment [7]. Many studies have demonstrated that the degree of tumor response and the extent of residual disease after adjuvant chemotherapy are predictors of relapse and survival [8-10].

The response of the primary tumor or regional nodes has been monitored clinically by palpation and found unreliable as it tends to overestimate the number of complete remission while underestimating the number of non-responders [5]. While radiological monitoring, be it mammogram, ultrasound, magnetic resonant imaging (contrast enhanced) or radio-nuclide imaging, has been used by various authors with published results [11-14], the gold standard modalities (breast magnetic resonance imaging and pathologic response) for monitoring response to NAC [5] are however not always possible in the subSahara African setting for reasons of affordability, limited technology penetration and large specialist to patient ratio.

However, breast ultrasonography has become an accepted adjunct to mammography for the evaluation of the breast after treatment for cancer in most countries in sub-Saharan Africa because it is readily available, affordable, non- invasive and is employed as an alternative diagnostic tool in assessing breast pathologies.

We set out to determine the objective response rate of LABC to NAC using breast ultrasound scan in characterizing and evaluating these responses. We also sought for the clinico-pathologic factors that might predict response to NAC. The findings from this work are the thrust of this paper.

${ }^{*}$ Correspondence to: Ayandipo OO, Division of Oncology, Department of Surgery, College of Medicine, University of Ibadan and University College Hospital, Ibadan, Nigeria, Tel: 234-8051249319, E-mail: yokebukola@yahoo.com

Received: May 29, 2018; Accepted: July 20, 2018; Published: July 23, 2018 


\section{Materials and methods}

This was a prospective cross-sectional study of ultrasound assessment of response of women with LABC to neo-adjuvant chemotherapy. Institutional ethical approval was obtained prior to the commencement of the study. All consecutive patients presenting with locally advanced breast carcinoma (Stage IIb-Stage IIIC) at the surgical out-patients clinic of the University College Hospital, Ibadan between January and December 2013 were recruited. Tissue diagnosis was confirmed either with a fine needle aspiration cytology (FNAC) or core needle biopsy. Individuals less than 18 years or above 70 years, those with metastatic breast cancer or early stage breast cancer (Stage IIIa), male breast cancer patients and those who declined participation were excluded from the study. This was a prospective cross-sectional study and a total of 120 consecutively diagnosed women with LABC were recruited. Pre-treatment evaluation included a clinical breast examination (CBE), core biopsy/ fine needle aspiration cytology, radiologic investigations (chest $\mathrm{x}$-ray, abdomino-pelvic ultrasound scan, bone radionuclide scan) along with breast ultrasound scan. Breast ultrasonography was done using a Logiq PS ultrasound machine with 7.5-10 MHz Linear probe to fully characterize the breast lump and assess skin thickening, architectural distortion and nipple retraction. The characteristics of the lump assessed with ultrasonography were pattern, location, size, shape, margins, echotexture, orientation, vascularity and attenuation. The number, size and morphology of the ipsilateral axillary lymphadenopathy was also assessed. Further work-up before commencing treatment included cardiac assessment (echocardiogram and electrocardiography) to ascertain fitness for anthracycline based chemotherapy and routine complete blood count. Neo-adjuvant treatment entailed anthracycline based chemotherapy (Epirubicin@100 $\mathrm{mg} / \mathrm{m}^{2}$ and Cyclophosphamide@1000 mg/m² ) at 3 weeks intervals. Prechemotherapy medications included dexamethasone, ondansetron and chlorpheniramine given intravenously at least thirty minutes before infusing the chemotherapeutic agents. The protocol of the study for each patient consisted of pre-chemotherapy breast ultrasound scan, chemotherapy infusion, and repeat breast ultrasound scan before subsequent chemotherapy administrations.

In the ultrasound suit, the patient was placed in supine position with the ipsilateral arm positioned above the head. The breast was scanned in both longitudinal and transverse planes with radial and antiradial planes used to illustrate the breast anatomy better. Lump size measurement was taken in 3 dimensions (breadth, width and length) with a product of the maximum two used in monitoring and assessing response. The above measurements were taken thrice, and the average recorded to minimize intra-observer variation. Tumor response was correlated with the standard International Union against Cancer (UICC) criteria [15]. Other data collected from the patient's records included demographic information, clinico-pathologic findings and clinical response.

Statistical analysis was done using SPSS version 18.0 for windows vista. Descriptive statistics included frequency tables, means, standard deviations, graphs and diagrams. Parametric paired comparisons of mean values were performed using the paired t-test. Measure of agreement between ultrasound and clinical breast examination was evaluated using Cohens Kappa method. $P$ value of $<0.05$ was considered significant (95\% confidence interval).

\section{Results}

A total of 120 consecutive patients with LABC receiving anthracycline-based chemotherapy was recruited. The mean age was
$44.17 \pm 9.07$ (range $25-70$ years). Two-fifths (40\%) were in the 40-49 age group. The mean weight and height was $71.73 \pm 15.9 \mathrm{~kg}$ and 1.64 $\pm 0.1 \mathrm{~m}$ respectively. About a quarter (26.7\%) were obese with BMI $\geq$ 30. A fifth of the pathologic diagnosis was achieved by cytology while four-fifths were by core biopsy.

Table 1 shows the demographic and clinico-pathologic characteristics while table 2 shows the ultrasound scan findings of the malignant breast lesions.

The average pre-chemotherapy breast lump diameter on clinical examination was $11.43 \pm 4.42 \mathrm{~cm}$. This figure reduced to $6.26 \pm 2.42 \mathrm{~cm}$ on ultrasound scan (USS) (Table 3 ). The widest diameter on clinical breast examination (CBE) ranged from $4.8-20 \mathrm{~cm}$ against $2.5-11.9 \mathrm{~cm}$ from USS ( $p$ value $<0.001$ ). The axillary nodal state was missed in 6 patients (5\%) on CBE. There was concordance with the USS findings in the remaining 114 (95\%) patients. The ultrasound scan was able to delineate multiple discrete lesions in the breast in 42 (35\%) patients as against 2 (1.7\%) patients on CBE when measured before commencement of neo-adjuvant chemotherapy. The mean post chemotherapy tumor diameter was $2.82 \pm 1.72 \mathrm{~cm}(0-8.9 \mathrm{~cm})$. Comparisons of the mean of pre and post chemotherapy diameters showed a significant difference with $p$ value $<0.001$.

The level of agreement between CBE and USS for tumor size and lymph node status was 60\% (Kappa 0.063) and 91.6\% (Kappa 0.405)

Table 1. Demographics and clinic-pathologic characteristics

\begin{tabular}{|c|c|c|c|}
\hline Characteristics & Mean (SD) & Number & Percentage \\
\hline $\begin{array}{l}\text { Side of tumor } \\
\text { Right } \\
\text { Left }\end{array}$ & & $\begin{array}{l}60 \\
60\end{array}$ & $\begin{array}{l}50 \\
50\end{array}$ \\
\hline $\begin{array}{l}\text { Duration of lump } \\
\text { (months) }\end{array}$ & $9( \pm 7)$ & & \\
\hline $\begin{array}{l}\text { Age range } \\
25-29 \\
30-39 \\
40-49 \\
50-59 \\
60-69 \\
>70\end{array}$ & $44.17( \pm 9.07)$ & $\begin{array}{l}2 \\
38 \\
48 \\
22 \\
8 \\
2\end{array}$ & $\begin{array}{l}1.7 \\
31.7 \\
40.0 \\
18.3 \\
6.7 \\
1.7\end{array}$ \\
\hline $\begin{array}{l}\text { Weight } \\
\text { Height } \\
\text { BMI }\end{array}$ & $\begin{array}{l}71.73( \pm 15.9) \\
1.64( \pm 0.07) \\
26.68( \pm 5.56)\end{array}$ & & \\
\hline Age at menarche & $14.71( \pm 2.41)$ & & \\
\hline $\begin{array}{l}\text { Parity } \\
\text { Nulliparous } \\
\text { Multiple }\end{array}$ & & $\begin{array}{l}2 \\
118\end{array}$ & $\begin{array}{l}1.7 \\
98.3\end{array}$ \\
\hline $\begin{array}{l}\text { Contraceptive use } \\
\text { Yes } \\
\text { No }\end{array}$ & & $\begin{array}{l}16 \\
104\end{array}$ & $\begin{array}{l}14.4 \\
85.6\end{array}$ \\
\hline $\begin{array}{l}\text { Pre-menopause } \\
\text { Post-menopause }\end{array}$ & & $\begin{array}{l}82 \\
38\end{array}$ & $\begin{array}{l}68.3 \\
31.7\end{array}$ \\
\hline $\begin{array}{l}\text { Breast cancer stage } \\
\text { IIb } \\
\text { IIIa } \\
\text { IIIb } \\
\text { IIIc }\end{array}$ & & $\begin{array}{l}6 \\
24 \\
62 \\
28\end{array}$ & $\begin{array}{l}5.0 \\
20.0 \\
51.7 \\
23.3\end{array}$ \\
\hline $\begin{array}{l}\text { Histology types } \\
\text { IHC (72 patients) } \\
\text { ER + } \\
\text { ER - } \\
\text { PR + } \\
\text { PR - } \\
\text { Her2Neu + } \\
\text { Her2Neu - }\end{array}$ & & $\begin{array}{l}24 \\
48 \\
12 \\
60 \\
42 \\
30\end{array}$ & $\begin{array}{l}33.3 \\
66.6 \\
16.7 \\
85.7 \\
58.3 \\
41.7\end{array}$ \\
\hline
\end{tabular}


Table 2. Breast ultrasound scan findings of malignant lumps

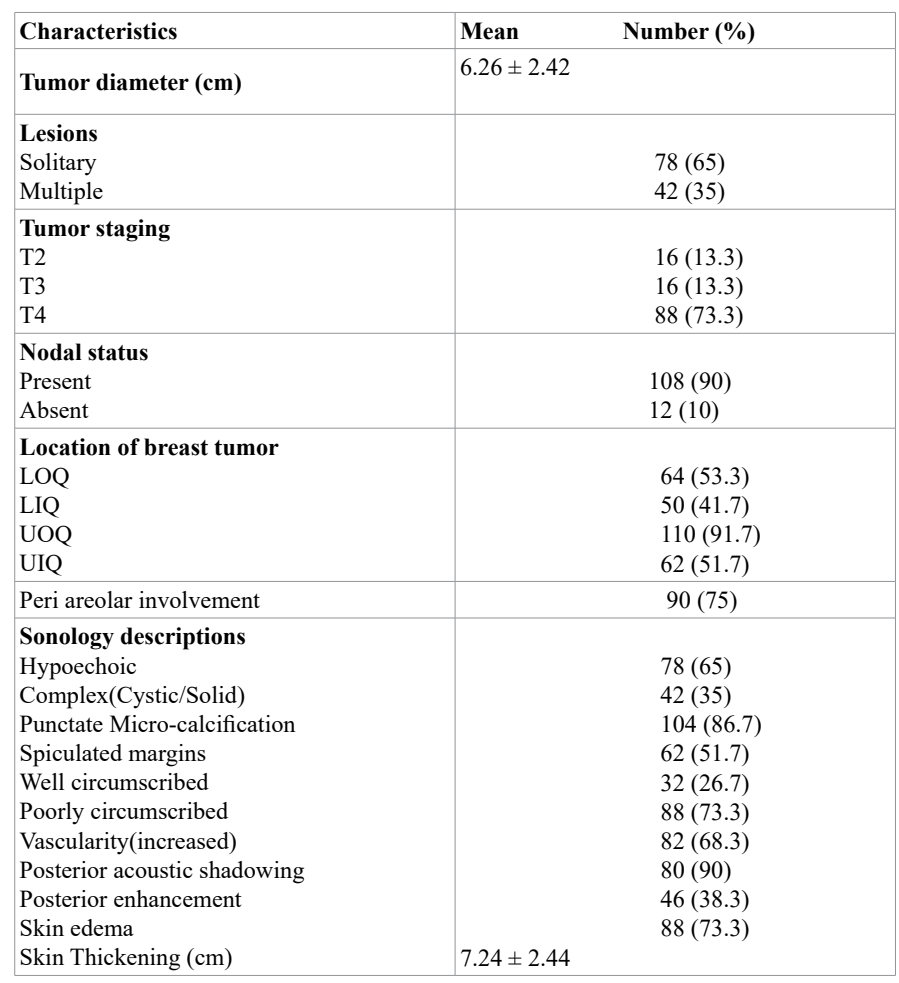

Table 3. The mean diameters of pre and post chemotherapy diameters in CBE and USS

\begin{tabular}{|l|l|l|}
\hline Assessment method & Mean tumor diameter (cm) & $\boldsymbol{p}$ value \\
\hline Clinical breast examination & $\begin{array}{l}\text { Pre- } 11.43 \pm 4.42 \\
\text { Post- } 8.09 \pm 2.08 \\
\text { Pre-6.26 } \pm 2.42 \\
\text { Post- } 2.82 \pm 1.72\end{array}$ & \\
Ultrasound & $<0.001$ \\
\hline
\end{tabular}

respectively. Using the UICC criteria, partial response was noted in 100 $(83.3 \%)$ patients and complete response in $6(5 \%)$, while $8(6.7 \%)$ and 6 (5\%) had stable and progressive disease respectively. Parity was noted to be associated with tumor response $(p-0.014)$ with stable disease in all nullipara and complete/partial response seen in women with two or more children (90.2\%). We found no association between menopause, tumor grade, nodal grade, tumor stage or immunohistochemistry status and response to NAC. Of importance is that all patients with no axilla metastasis had complete response $(p=0.008)$ to chemotherapy. No tumor greater than $5 \mathrm{~cm}$ demonstrated complete response $(p=0.95)$. In comparing the pre-chemotherapy mean tumor diameter between responders (partial/complete) versus non-responders (stable or disease progression); it was higher in non-responders $(7.84 \pm 2.77 \mathrm{~cm})$ than in non-responders $(6.05 \pm 2.32 \mathrm{~cm})$, although this was not statistically significant $(p-0.07)$. In multiple logistic regression analysis, none of the selected variables was a positive predictor of tumor response to NAC.

\section{Discussion}

Collaborative meta-analysis on outcome of use of anthracycline based chemotherapeutic (AC) regimen showed superiority over the traditional Cyclophosphamide-Methotrexate and 5Fluoro-uracil regimen (CMF) combination by demonstrating a reduction of the annual breast cancer death by $38 \%$ for pre-menopausal women and $20 \%$ for post-menopausal women [16] in women placed on the AC regimen. Studies have shown that palpation (CBE) overestimates the number of remission- either complete or partial relative to radiologic assessment while pathologic assessment is regarded as the gold standard in assessing response to neo-adjuvant chemotherapy [5]. The proliferative function of breast tumor represented by KI-67 is expressed differently in pre-chemotherapy versus post-chemotherapy samples and anthracycline treatment results in a significant decrease of mitotic activity [17-19]. Thus, a decreased KI-67 expression is not just a monitor of response to treatment but also an independent predictor of response to anthracycline based chemotherapy [5].

Our findings of two-thirds having intermediate or high-grade disease and a concomitant response to NAC buttress the findings by Wang et al that high mitotic count lesion had more significant response than tumors with lesser mitotic count [20]. The pathogenesis for this being the hyper proliferative state which renders the tumor more sensitive to Anthracycline chemotherapy and clinical implication is that it renders them more susceptible to the structural damage induced during DNA synthesis, thus leading to a decreased viability of newly formed cells [21-23]. Although the molecular subtypes was obtained in two-thirds of patients, we found no association between the molecular subtypes (ER/PR/Her2) and response to NAC, however the basal-like (ER/PR/Her2 negative) patients manifested stable disease or partial response more, this is in keeping with reports from other parts of the world that basal-like (ER/PR/Her2 negative) breast carcinoma are more sensitive to anthracycline based chemotherapy $[5,10,24]$. There have been conflicting reports about Her2/neu expression as a predictor of response to anthracycline chemotherapy [5,24,25]; In this study, we found no association between Her2/neu expression and response to NAC. The in-vivo response of a tumor generally reflects its chemo-sensitivity and if the response truly reflects the sensitivity of all tumor burden, both loco-regional and micro-metastases, the response should be positively correlated with outcome [5]. Most authors find no association between clinical/ pathologic response and outcome (disease free survival and overall survival) [5,26].

The common ultrasound features of malignancy noted in another study [27] was also found in at least two-thirds of recruited patients and were consistent with the "BIRADS" descriptor [28] for malignant breast masses. A spiculated margin in the setting of an irregular shaped mass has indeed been noted to have a positive predictive value in about $62-85 \%$ range for malignancy [27], of which our findings fall within the quoted range. In our study, ultrasound was able to detect more multifocal/ multicentric disease in up to a third of patients when clinical breast examination showed unifocal disease at the prechemotherapy assessment stage; this is clearly higher than in a previous review [8] where only an additional $10 \%$ was discovered in their study subjects. One explanation for missing such a substantial number is that peri-tumoral edema and skin involvement mask or reduce proper delineation of other satellite lumps in the ipsilateral breast, thereby causing over estimation of the tumor size clinically. Indeed, the same reasons explain the significant difference in the mean tumor size measured in favor of by CBE over USS. Of note also, is the relevance of excessive posterior acoustic shadowing of the tumor on ultrasound scan which may reduce visualization of the posterior margins of the tumor. Axillary nodal staging was missed in 5\% of patients by $\mathrm{CBE}$, this was clearly picked up by USS, this further buttressing the advantage of ultrasound over $\mathrm{CBE}$ in the clinical staging of patients. Our study findings on tumor staging between CBE and USS align with the findings of Sperber et al. [8] while Yeh et al. [29] reported a lower level (48\%) of agreement between CBE and USS in their series. The down-staging of an additional $10 \%$ of stage III cancer to stage II in our study demonstrates the superiority of USS to CBE in assessment 
of patients' response to treatment. Subjective tumor responses that were not measurable in the post-chemotherapy setting were improved tumor margin delineation noted in figures 1 and 2 respectively.

The superiority of the USS in delineating breast lumps than mammography is clear in the pre-chemotherapy setting than in the post-chemotherapy size assessment setting [30-33]. The implication in a setting where $\mathrm{LABC}$ is the norm [33-35], is that initial staging by a verified tool (USS) ensures proper staging and need for neo-adjuvant treatment or not. From a previous work, only a negligible fraction of our patients received breast conserving surgery (BCS) [7], whilst BCS is the gold- standard in developed parts of the world. Reasons for this are that in such parts of the world, most tumors are screen detected and are early stage disease. The efficacy of BCS viz-a-viz modified radical mastectomy (MRM) in early breast cancer has long been established [36-39]. Important findings in our study militating against BCS is the involvement of the nipple-areolar complex, demonstrated in threequarter of patients by ultrasound; which contrasts sharply with the less than a fifth quoted in a previous study [40], so also, the increased diagnosis of multi-centric disease by ultrasound when compared to CBE. The level of correlation between CBE and USS nodal staging tallied with previous findings [8]. Overall, we found that the greater the nodal disease burden, the less the response to chemotherapy. There was no significant association between the histologic grade, tumor stage or immunohistochemistry and the response to NAC, as was noted previously [40]. Following NAC, the non-measurable (subjective) response noted in our study subjects were akin to the findings by Kumer et al. [41], and these included improved tumor margins definition and reduction in skin edema. Our study results compare favorably with earlier epochs both within the sub-region and in Europe $[42,43]$ in terms of response using the RECIST criteria [15].

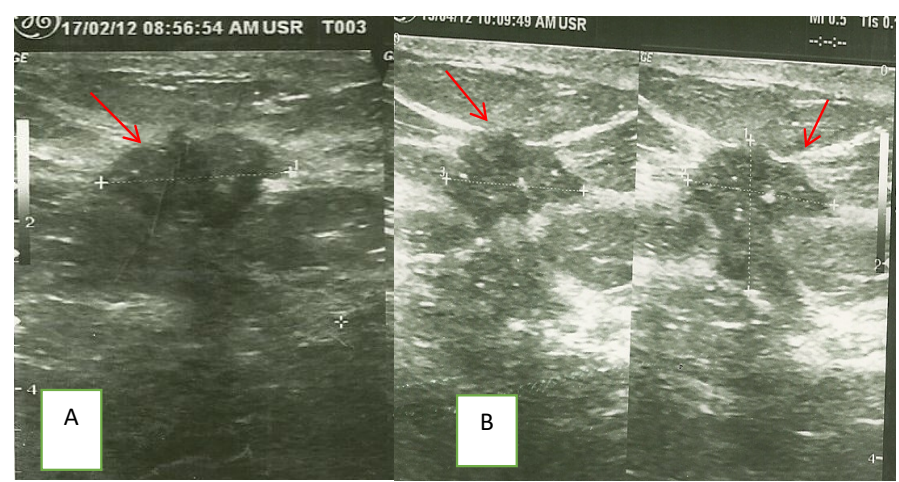

Figure 1. (A) Pre and (B) Post- chemotherapy ultrasound images of a patient's improved definition of tumor margin (arrows) after two cycles of chemotherapy

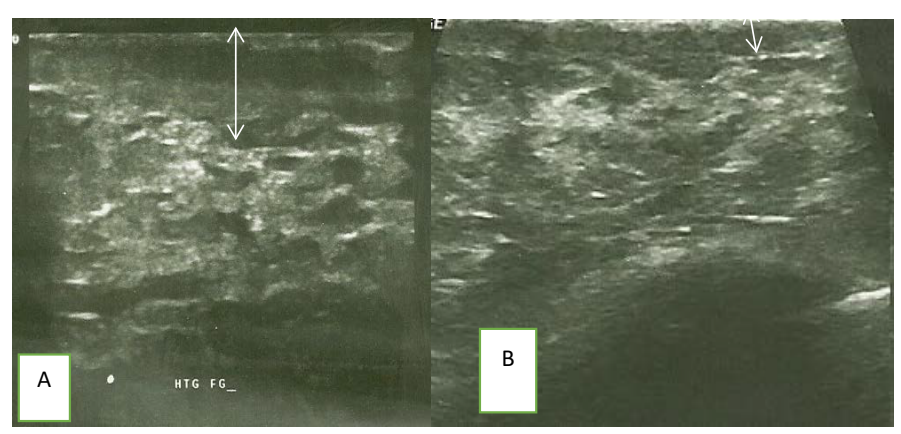

Figure 2. (A) Pre and (B) Post- chemotherapy ultrasound images of another patient demonstrating reduction in skin thickness (arrows) after a course of chemotherapy

\section{Limitations}

The gold standard modalities (pathologic response and Breast magnetic resonance imaging) in assessing response to neoadjuvant chemotherapy were not done in this study because of cost. Lack of routine analysis of patient's hormonal receptor status (immunohistochemistry) was also noted.

\section{Conclusion}

Anthracycline based NAC has been shown to be effective sonographically in downstaging LABC in our setting whilst the breast ultrasound scan is a cheap and veritable diagnostic radiological tool in tumor and nodal staging while also assessing more effectively the response to NAC when compared to CBE.

\section{References}

1. Makris A, Powles TJ, Ashley SE, Chang J, Hickish T, et al. (1998) A reduction in the requirements for mastectomy in a randomized trial of neoadjuvant chemo endocrine therapy in primary breast cancer. Ann Oncol 9: 1179-1184. [Crossref]

2. Mauriac L, MacGrogan G, Avril A, Durand M, Floquet A, et al. (1999) Neoadjuvant chemotherapy for operable breast carcinoma larger than $3 \mathrm{~cm}$ : a unicentre randomized trial with a 124-month median follow-up. Ann Oncol 10: 47-52. [Crossref]

3. Gunduz N, Fisher B, Saffer EA (1979) Effect of surgical removal on the growth and kinetics of residual tumor. Cancer Res 39: 3861-3865. [Crossref]

4. Fisher B, Gunduz N, Saffer EA (1983) Influence of the interval between primary tumor removal and chemotherapy on kinetics and growth of metastases. Cancer Res 43: 14881492. [Crossref]

5. Faneyte IF, Schrama JG, Peterse JL, Remijnse PL, Rodenhuis S, et al. (2003) Breast cancer response to neoadjuvant chemotherapy: predictive markers and relation with outcome. Br J Cancer 88: 406-412. [Crossref]

6. Kingham TP, Alatise OI, Vanderpuye V, Casper C, Abantanga FA, et al. (2013) Treatment of cancer in sub-Saharan Africa. Lancet Oncol 14: 58-167. [Crossref]

7. Ogundiran TO, Ayandipo OO, Ademola AF, Adebamowo CA (2013) Mastectomy for management of breast cancer in Ibadan, Nigeria. BMC Surg 13: 59. [Crossref]

8. Fisher B, Bryant J, Wolmark N, Mamounas E, Brown A, et al. (1998) Effect of preoperative chemotherapy on the outcome of women with operable breast cancer. $J$ Clin Oncol 16: 2672-2685. [Crossref]

9. Cance WG, Carey LA, Calvo BF, Sartor C, Sawyer L, et al. (2002) Long-term outcome of neoadjuvant therapy for locally advanced breast carcinoma: effective clinical downstaging allows breast preservation and predicts outstanding local control and survival. Ann Surg 236: 295-302. [Crossref]

10. Kuerer HM, Newman LA, Smith TL, Ames FC, Hunt KK, et al. (1999) Clinical course of breast cancer patients with complete pathologic primary tumor and axillary lymph node response to doxorubicin-based neoadjuvant chemotherapy. J Clin Oncol 17: 460469. [Crossref]

11. Sperber F, Weinstein Y, Sarid D, Ben Yosef R, Shalmon A, et al. (2006) Preoperative clinical, mammographic and sonographic assessment of neoadjuvant chemotherapy response in breast cancer. Isr Med Assoc J 8: 342-346. [Crossref]

12. Tiling R, Linke R, Untch M, Richter A, Fieber S, et al. (2001) 18 F-FDG PET and 99m Tc-sestamibi scintimammography for monitoring breast cancer response to neoadjuvant chemotherapy: a comparative study. Eur J Nucl Med 28: 711-720. [Crossref]

13. Julius T, Kemp SE, Kneeshaw PJ, Chaturvedi A, Drew PJ, et al. (2005) MRI and conservative treatment of locally advanced breast cancer. Eur J Surg Oncol 31: 11291134. [Crossref]

14. Abraham DC, Jones RC, Jones SE, Cheek JH, Peters GN, et al. (1996) Evaluation of neoadjuvant chemotherapeutic response of locally advanced breast cancer by magnetic resonance imaging. Cancer 78: 91-100. [Crossref]

15. Therasse P, Arbuck SG, Eisenhauer EA, Wanders J, Kaplan RS, et al. (2000) New guidelines to evaluate the response to treatment in solid tumors. European Organization for Research and Treatment of Cancer, National Cancer Institute of the United States, National Cancer Institute of Canada. J Natl Cancer Inst 92: 205-216. [Crossref]

16. Early Breast Cancer Trialists' Collaborative Group (2005) Effects of chemotherapy and hormonal therapy for early breast cancer on recurrence and 15-year survival: an overview of the randomised trials. Lancet 365:1687-1717. [Crossref] 
17. Honkoop AH, Pinedo HM, De Jong JS, Verheul HM, Linn SC, et al. (1997) Effects of chemotherapy on pathologic and biologic characteristics of locally advanced breast cancer. Am J Clin Pathol 107: 211-218. [Crossref]

18. Linn SC, Pinedo HM, van Ark-Otte J, van der Valk P, Hoekman K, et al. (1997) Expression of drug resistance proteins in breast cancer, in relation to chemotherapy. Int J Cancer 71: 787-795. [Crossref]

19. Schneider J, Lucas R, Sánchez J, Ruibal A, Tejerina A, et al. (2000) Modulation of molecular marker expression by induction chemotherapy in locally advanced breast cancer: correlation with the response to therapy and the expression of MDR1 and LRP. Anticancer Res 20: 4373-4377. [Crossref]

20. Wang J, Buchholz TA, Middleton LP, Allred DC, Tucker SL, et al. (2002) Assessment of histologic features and expression of biomarkers in predicting pathologic response to anthracycline-based neoadjuvant chemotherapy in patients with breast carcinoma. Cancer 94: 3107-3114. [Crossref]

21. Colleoni M, Orvieto E, Nolé F, Orlando L, Minchella I, et al. (1999) Prediction of response to primary chemotherapy for operable breast cancer. Eur J Cancer 35: 574 579. [Crossref]

22. Makris A1, Powles TJ, Allred DC, Ashley SE, Trott PA, et al. (1999) Quantitative changes in cytological molecular markers during primary medical treatment of breast cancer: a pilot study. Breast Cancer Res Treat 53: 51-59. [Crossref]

23. Billgren AM, Rutqvist LE, Tani E, Wilking N, Fornander T, et al. (1999) Proliferating fraction during neoadjuvant chemotherapy of primary breast cancer in relation to objective local response and relapse-free survival. Acta Oncol 38: 597-601. [Crossref]

24. MacGrogan G, Mauriac L, Durand M, Bonichon F, Trojani M, et al. (1996) Primary chemotherapy in breast invasive carcinoma: predictive value of the immunohistochemical detection of hormonal receptors, p53, c-erbB-2, MiB1, pS2 and GST pi. Br J Cancer 74: 1458-1465. [Crossref]

25. Hamilton A, Piccart M (2000) The contribution of molecular markers to the prediction of response in the treatment of breast cancer: a review of the literature on HER-2, p53 and BCL-2. Ann Oncol 11: 647-663. [Crossref]

26. Gajdos C, Tartter PI, Estabrook A, Gistrak MA, Jaffer S, et al. (2002) Relationship of clinical and pathologic response to neoadjuvant chemotherapy and outcome of locally advanced breast cancer. J Surg Oncol 80: 4-11. [Crossref]

27. Hong AS, Rosen EL, Soo MS, Baker JA (2005) BI-RADS for sonography: positive and negative predictive values of sonographic features. AJR Am J Roentgenol 184 1260-1265. [Crossref]

28. Eberl MM, Fox CH, Edge SB, Carter CA, Mahoney MC (2006) BI-RADS classification for management of abnormal mammograms. J Am Board Fam Med 19: 161-164. [Crossref]

29. Yeh E, Slanetz P, Kopans DB, Rafferty E, Georgian-Smith D, et al. (2005) Prospective comparison of mammography, sonography, and MRI in patients undergoing neoadjuvant chemotherapy for palpable breast cancer. AJR Am J Roentgenol 184: 868877. [Crossref]
30. Fornage BD, Toubas O, Morel M (1987) Clinical, mammographic, and sonographic determination of preoperative breast cancer size. Cancer 60: 765-771. [Crossref]

31. Herrada J, Iyer RB, Atkinson EN, Sneige N, Buzdar AU, et al. (1997) Relative value of physical examination, mammography, and breast sonography in evaluating the size of the primary tumor and regional lymph node metastases in women receiving neoadjuvant chemotherapy for locally advanced breast carcinoma. Clin Cancer Res 3 : 1565-1569. [Crossref]

32. Hieken TJ, Harrison J, Herreros J, Velasco JM (2001) Correlating sonography, mammography, and pathology in the assessment of breast cancer size. Am J Surg 182 : 351-354. [Crossref]

33. Gawne-Cain ML, Smith E, Darby M, Given-Wilson R (1995) The use of ultrasound for monitoring breast tumour response to pro-adjuvant therapy. Clin Radiol 50: 681-686. [Crossref]

34. Ikpatt OF, Kuopio T, Collan Y (2002) Proliferation in African breast cancer: biology and prognostication in Nigerian breast cancer material. Mod Pathol 15: 783-789. [Crossref]

35. Huo D, Ikpatt F, Khramtsov A, Dangou JM, Nanda R, et al. (2009) Population differences in breast cancer: survey in indigenous African women reveals overrepresentation of triple-negative breast cancer. J Clin Oncol 27: 4515-4521. [Crossref]

36. Lee S, Kim SW, Kim SK, Lee KS, Kim EA, et al. (2011) Locoregional recurrence of breast conserving surgery after preoperative chemotherapy in Korean women with locally advanced breast cancer. J Breast Cancer 14: 289-295. [Crossref]

37. Jatoi I (2012) Options in breast cancer local therapy: who gets what? World J Surg 36 1498-1502. [Crossref]

38. Zurrida S, Bassi F, Arnone P, Martella S, Del Castillo A, et al. (2011) The changing face of mastectomy (from mutilation to aid to breast reconstruction). Int J Surg Oncol 2011: 980158. [Crossref]

39. Litière S, Werutsky G, Fentiman IS, Rutgers E, Christiaens MR, et al. (2012) Breast conserving therapy versus mastectomy for stage I-II breast cancer: 20-year follow-up of the EORTC 10801 phase 3 randomised trial. Lancet Oncol 13: 412-419. [Crossref]

40. Warren RM, Bobrow LG, Earl HM, Britton PD, Gopalan D, et al. (2004) Can breast MRI help in the management of women with breast cancer treated by neoadjuvant chemotherapy? Br J Cancer 90: 1349-1360. [Crossref]

41. Kumar A, Agrawal S, Shukla RC (1998) Sonomammography an objective tool for assessment of chemotherapeutic response in locally advanced breast cancer. European Journal of Cancer 34: S16-S17.

42. Anyanwu SN, Nwose P, Ihekwoaba E, Mbaeri AT, Chukwuanukwu TO (2010) Neoadjuvant chemotherapy for locally advanced pre-menopausal breast cancer in Nigeria women: Early experience. Niger J Clin Pract 13: 215-217. [Crossref]

43. Eltahir A, Heys SD, Hutcheon AW, Sarkar TK, Smith I, et al. (1998) Treatment of large and locally advanced breast cancers using neoadjuvant chemotherapy. Am J Surg 175 127-132. [Crossref]

Copyright: (C2018 Soyemi TO. This is an open-access article distributed under the terms of the Creative Commons Attribution License, which permits unrestricted use, distribution, and reproduction in any medium, provided the original author and source are credited. 